\title{
Three Concomitant Crystal Forms of Monomeric Cobalt Chloride with 3-Pyridinemethanol
}

\author{
Miha Trdin,* Ivan Leban and Nina Lah \\ University of Ljubljana, Faculty of Chemistry and Chemical Technology, Večna pot 113, 1000 Ljubljana \\ *Corresponding author: E-mail: miha.trdin@fkkt.uni-lj.si
}

Received: 11-09-2014

Dedicated to the memory of Prof. Dr. Jurij V. Brenčič.

\begin{abstract}
Three new crystal forms of a mononuclear cobalt(II) chloride with 3-pyridinemethanol (3PM), $\mathrm{CoCl}_{2}(3 \mathrm{PM})_{4}$, have been prepared: triclinic $(P \overline{1})$ and monoclinic $\left(P 2_{1} / c\right)$ polymorphs and its dihydrate which crystallises in the triclinic $P \overline{1}$ space group. The three crystal forms differ by the orientation of 3PM ligands in the mononuclear entities and consequently in their packing arrangements. All three forms crystallise concomitantly. Their crystal structures have been determined at $150 \mathrm{~K}$.
\end{abstract}

Keywords: Pyridine alcohols, cobalt(II) chloride, polymorphs, dihydrate

\section{Introduction}

One of the most important areas of research in coordination chemistry is the synthesis and characterisation of coordination polymers. ${ }^{1-4}$ To understand how the metalorganic building blocks assemble to form larger architectures, the scientists have to understand the driving forces behind the aggregation of these blocks. Although the modern theoretical chemistry can be an effective tool to predict the molecular structures, the aggregation prediction remains unsuccessful in most cases. ${ }^{5}$

In the course of the preparation of new coordination complexes we have used simple pyridine alcohols as ligands capable to connect the metal centres into larger polynuclear architectures. These simple commercially available ligands contain two functional groups: i) pyridine nitrogen atom and ii) hydroxo group of a pyridine side chain. Both can participate in coordination to metal centres either in chelating or bridging manner. Additionally the hydroxo group may be deprotonated to give the alkoxo group, known as a good bridging species. The aggregation of the building blocks however, is not exclusively governed by strong covalent or coordination bonds. The ability of the pyridine ring to participate in $\pi \cdots \pi$ stacking interactions and $\mathrm{C}-\mathrm{H} \cdots \pi$ hydrogen bonds and the ability of the hydroxo group of the side chain to form intermolecular hydrogen bonds can therefore give a unique view on the driving forces behind the crystal formation. ${ }^{6,7}$ The aggregation of the molecules however, is not unambiguous. If molecules can interact in more than one way, two or even more crystal forms that differ primarily by the intermolecular interactions can be obtained from the same reaction mixture simultaneously. This is known as concomitant polymorphism. ${ }^{8}$

We have previously reported on a case of a polymorphic transition metal coordination compound where different $\pi \cdots \pi$ stacking interactions and $\mathrm{C}-\mathrm{H} \cdots \pi$ hydrogen bonds between the pyridine rings of a simple pyridine alcohol ligand, 2-pyridineethanol, play a vital role in the packing arrangements of the polymorphs. The compound $\mathrm{Ni}(\mathrm{Ac})_{2}(2 \mathrm{PE})_{2}$, where $\mathrm{Ac}$ is acetate and $2 \mathrm{PE}$ is 2pyridineethanol, crystallises in three different polymorphic forms: Two crystallise concomitantly from acetonitrile solution, ${ }^{9}$ while the third polymorphic form was obtained in the presence of potassium oxalate monohydrate in the reaction mixture. ${ }^{10}$ Herein we report a cobalt(II) chloride complex with 3-pyridinemethanol (3PM), (Scheme 1), which crystallises concomitantly

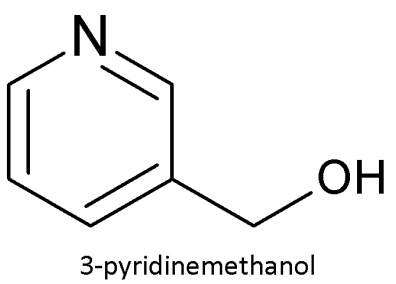

Scheme 1. Ligand used in this work. 
from the same reaction mixture in three forms: two polymorphic forms and a dihydrate. Their crystal structures are described and their packing analysed and compared.

\section{Experimental}

\section{1. General Considerations}

Chemicals were purchased from Aldrich or Fluka and were used without further purification.

\section{2. Preparation of $\mathrm{CoCl}_{2}(3 \mathrm{PM})_{4}$ and $\mathrm{CoCl}_{2}(3 \mathrm{PM})_{4} \cdot 2 \mathrm{H}_{2} \mathrm{O}$}

The reaction between $\mathrm{CoCl}_{2} \cdot 6 \mathrm{H}_{2} \mathrm{O}$ and 3-pyridinemethanol in methanol afforded prismatic purple crystals later identified as a mixture of two polymorphic forms ( 1 and 2) and a dihydrate (3). 3-pyridinemethanol (0.30 mL) was added to $8 \mathrm{~mL}$ of methanol. The mixture was then stirred and heated to the boiling point before $\mathrm{CoCl}_{2} \cdot 6 \mathrm{H}_{2} \mathrm{O}$ $(0.15 \mathrm{~g})$ was gradually added during the intense stirring. The resulting dark blue solution was allowed to slowly cool down to ambient temperature in an opened $50 \mathrm{~mL}$ Erlenmeyer flask. Prismatic purple crystals precipitated after two hours.

\subsection{X-ray Crystallography}

Data were collected on an Agilent SuperNova diffractometer with an Atlas detector using the mirror monochromated Mo $K \alpha$ radiation at $150 \mathrm{~K}$. Data reduction and integration were performed with the CrysAlis Pro software package. ${ }^{11}$ The structures were solved by direct methods implemented in SIR92. ${ }^{12}$ The positions of the remaining non-hydrogen atoms were found in difference Fourier maps during the subsequent least-squares refinement using the SHELX program. ${ }^{13}$ All non-hydrogen atoms were refined anisotropically. Hydrogen atoms were found in difference Fourier maps but were included in the final refinement cycles on their calculated positions and refined as riding on their parent atoms. Exceptions were only the hydrogen atoms of the hydroxy groups in $\mathbf{1}$ and $\mathbf{2}$. They were located in the difference Fourier maps and freely refined. The water hydrogens in $\mathbf{3}$ were found in the difference Fourier map but could not be refined properly. Figures depicting the structures were prepared by ORTEP-III, Mercury and CrystalMaker. ${ }^{14-16}$ A summary of the crystallographic data and structure refinements is given in Table 1. The relevant bond distances and angles are listed in Table 2. X-ray powder diffraction data were collected using a PANalytical X'Pert PRO MPD diffractometer with $\theta-2 \theta$ reflection geometry, primary side Johansson type monoc-

Table 1. Crystallographic data for 1,2 and 3.

\begin{tabular}{|c|c|c|c|}
\hline & 1 & 2 & 3 \\
\hline Formula & $\mathrm{C}_{24} \mathrm{H}_{28} \mathrm{Cl}_{2} \mathrm{CoN}_{4} \mathrm{O}_{4}$ & $\mathrm{C}_{24} \mathrm{H}_{28} \mathrm{Cl}_{2} \mathrm{CoN}_{4} \mathrm{O}_{4}$ & $\mathrm{C}_{24} \mathrm{H}_{32} \mathrm{Cl}_{2} \mathrm{CoN}_{4} \mathrm{O}_{6}$ \\
\hline Formula weight & 566.33 & 566.33 & 598.33 \\
\hline Space group & $P 2_{1} / c$ & $P \overline{1}$ & $P \overline{1}$ \\
\hline$Z$ & 2 & 1 & 1 \\
\hline$T(\mathrm{~K})$ & 150 & 150 & 150 \\
\hline$a(\AA)$ & $7.7584(2)$ & $7.5042(5)$ & $7.7216(4)$ \\
\hline$b(\AA)$ & $19.8228(3)$ & $8.5017(5)$ & $8.8205(5)$ \\
\hline$c\left(^{\circ}\right)$ & $8.4517(2)$ & $11.1418(8)$ & $11.0073(6)$ \\
\hline$\alpha\left(^{\circ}\right)$ & & $107.632(6)$ & $77.810(4)$ \\
\hline$\beta\left(^{\circ}\right)$ & $112.222(2)$ & $90.427(5)$ & $73.478(4)$ \\
\hline$\gamma\left({ }^{\circ}\right)$ & & $112.601(6)$ & $68.758(5)$ \\
\hline$V\left(\AA^{3}\right)$ & $1203.27(5)$ & $619.18(8)$ & $664.98(7)$ \\
\hline$\mu(\mathrm{Mo}-\mathrm{K} \alpha)\left(\mathrm{mm}^{-1}\right)$ & 0.98 & 0.95 & 0.89 \\
\hline$\rho_{\text {calc }}\left(\mathrm{g} \mathrm{cm}^{-3}\right)$ & 1.563 & 1.519 & 1.494 \\
\hline All reflections & 15556 & 5268 & 6417 \\
\hline Independent reflections & 3316 & 3204 & 3458 \\
\hline Observed reflections $\left[F^{2}>2 \sigma\left(F^{2}\right)\right]$ & 2884 & 2667 & 2683 \\
\hline$\theta_{\min }-\theta_{\max }\left({ }^{\circ}\right)$ & $3.0-30.4$ & $3.0-30.3$ & $2.9-30.3$ \\
\hline $\mathrm{R}_{\text {int }}$ & 0.032 & 0.026 & 0.033 \\
\hline $\mathrm{R}_{1}\left[F^{2}>2 \sigma\left(F^{2}\right)\right]$ & 0.033 & 0.036 & 0.043 \\
\hline $\mathrm{R}_{1}\left[F^{2}\right]^{\mathrm{a}}$ & 0.041 & 0.049 & 0.060 \\
\hline$w \mathrm{R}_{2}\left[F^{2}>2 \sigma\left(F^{2}\right)\right]^{\mathrm{b}}$ & 0.068 & 0.074 & 0.101 \\
\hline$w \mathrm{R}_{2}\left[F^{2}\right]^{\mathrm{b}}$ & 0.072 & 0.081 & 0.116 \\
\hline$S^{c}$ & 1.13 & 1.06 & 1.08 \\
\hline
\end{tabular}

${ }^{a} R=\Sigma|| F_{o}|-| F_{c}|| \Sigma F_{o} \mid \cdot{ }^{b} w R_{2}=\left\{\Sigma\left[w\left(F_{o}{ }^{2}-F_{c}{ }^{2}\right)^{2}\right] / \Sigma\left[w\left(F_{o}{ }^{2}\right)^{2}\right]\right\}^{1 / 2} .{ }^{c} S=\left\{\Sigma\left[\left(F_{o}{ }^{2}-F_{c}{ }^{2}\right)^{2}\right] /(n-p\}^{1 / 2}\right.$ where $n$ is the number of reflections and $p$ is the total number of parameters refined. 
hromator and $\mathrm{Cu} K \alpha_{1}(\lambda=1.54059 \AA)$ radiation. The ambient temperature XRD spectrum of a sample was acquired from $2 \theta$ angles of $5^{\circ}$ to $80^{\circ}$ in steps of $0.034^{\circ}$.

\section{Results and Discussion}

Although simple pyridine alcohols are commercially available compounds, they are not widely employed as ligands in coordination chemistry. For example, the CSD search afforded 41 hits of transition metal complexes with 3-pyridinemethanol as a neutral ligand and only 2 hits of transition metal complexes with 3-pyridinemethanol as an anionic ligand. ${ }^{17}$ Moreover, none of them is a cobalt coordination complex and only one complex has is reported having a $\operatorname{TrN}_{4} \mathrm{X}_{2}$ geometry observed in all three structures reported here. The copper coordination compound, $\mathrm{Cu}-$ $\mathrm{Cl}_{2}(3 \mathrm{PM})_{4}$, is isostructural with the triclinic polymorph 2 . It crystallises in the unit cell $16 \AA^{3}$ larger as that of $\mathbf{2}^{18}$
The reaction between $\mathrm{CoCl}_{2} \cdot 6 \mathrm{H}_{2} \mathrm{O}$ and $3 \mathrm{PM}$ in methanol afforded prismatic purple crystals which turned out to be a mixture of three crystal forms: two polymorphic forms of $\mathrm{CoCl}_{2}(3 \mathrm{PM})_{4}$ and a dihydrate Co$\mathrm{Cl}_{2}(3 \mathrm{PM})_{4} \cdot 2 \mathrm{H}_{2} \mathrm{O}$. The first polymorph crystallises in the monoclinic space group $P 2_{1} / c$, (1), while the second crystallises in the triclinic space group $P \overline{1}$ (2). The dihydrate 3 crystallises in the triclinic space group $P \overline{1}$. Since the three concomitantly crystallised forms could not be identified by their crystal habits, their discovery was an unexpected result of searching for a suitable crystal before a routine X-ray data collection. The reaction was repeated several times to confirm the reproducibility of the synthesis. The product was additionally characterised by X-ray powder diffraction and the simulated powder diffraction patterns and a powder diffraction pattern of the reaction product were compared (Figure 1).

The comparison of the measured diffractogram with the diffraction patterns simulated for the three known struc-

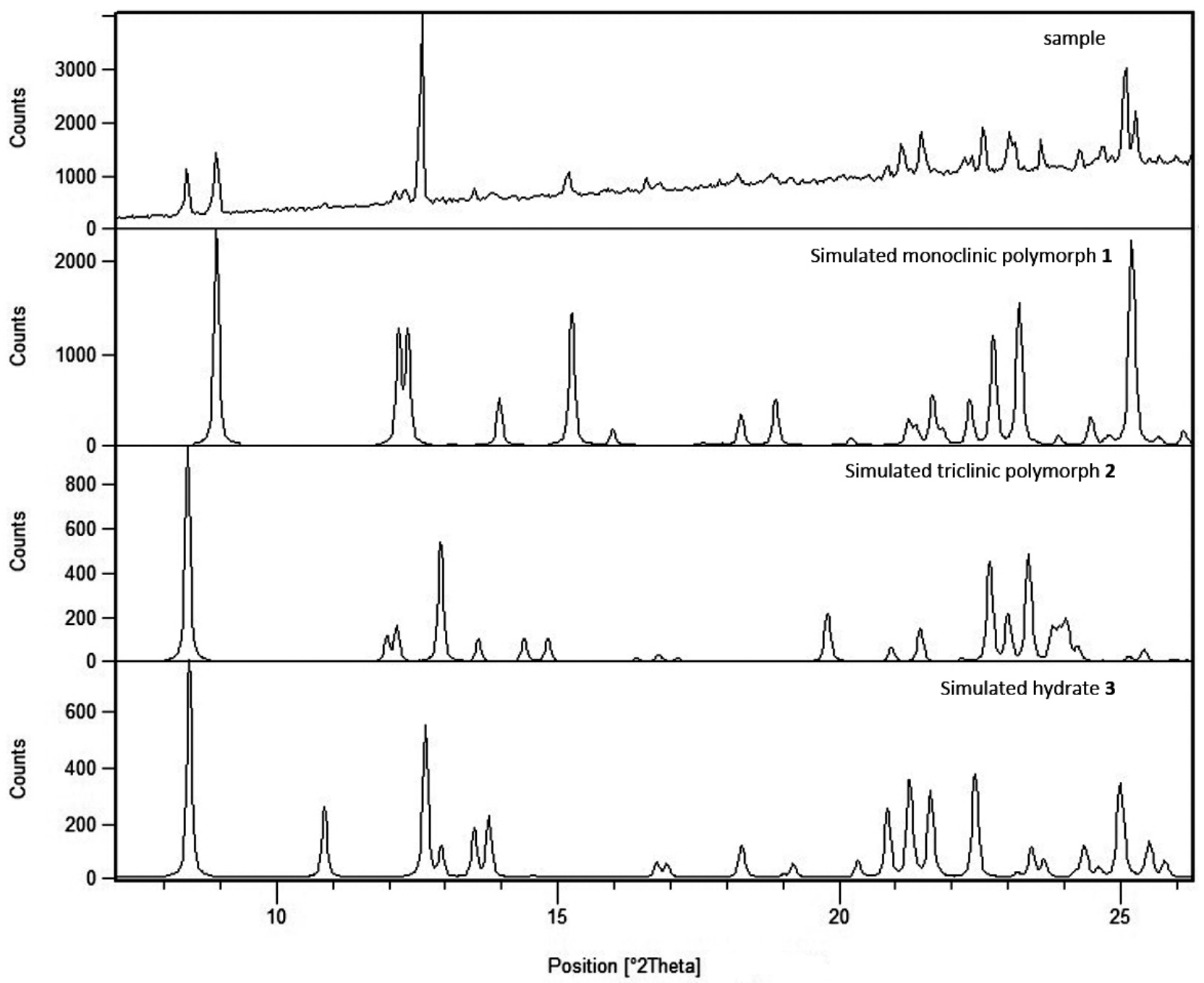

Figure 1. Comparison of the measured powder diffraction pattern of the reaction product and the simulated diffraction patterns of the two polymorphs and the dihydrate. 
tures confirmed the presence of polymorph $\mathbf{1}$ and the dihydrate $\mathbf{3}$ in the reaction product. Though the structure of polymorph $\mathbf{2}$ has been undoubtedly determined, its presence in the bulk material obtained with the crystallisation could not be neither confirmed nor dismissed by X-ray powder diffraction. This, however, does not negate the existence of the second polymorphic form. Its content was simply too low to be undoubtedly detected by powder diffraction.

\section{1. Molecular Structures of $\mathrm{CoCl}_{2}(3 \mathrm{PM})_{4}$ in 1,2 and 3}

In general, the molecular structures of Co$\mathrm{Cl}_{2}(3 \mathrm{PM})_{4}$ are similar in all three compounds. A molecule of $\mathbf{1}$ is depicted in Figure 2. A consistent atom labelling scheme was used for all three compounds. The Co ion is located on the inversion center and is coordinated by four 3-pyridinemethanol ligands and two chlorido ligands forming elongated octahedral arrangement. The two crystallographically distinct 3PM ligands are coordinated in

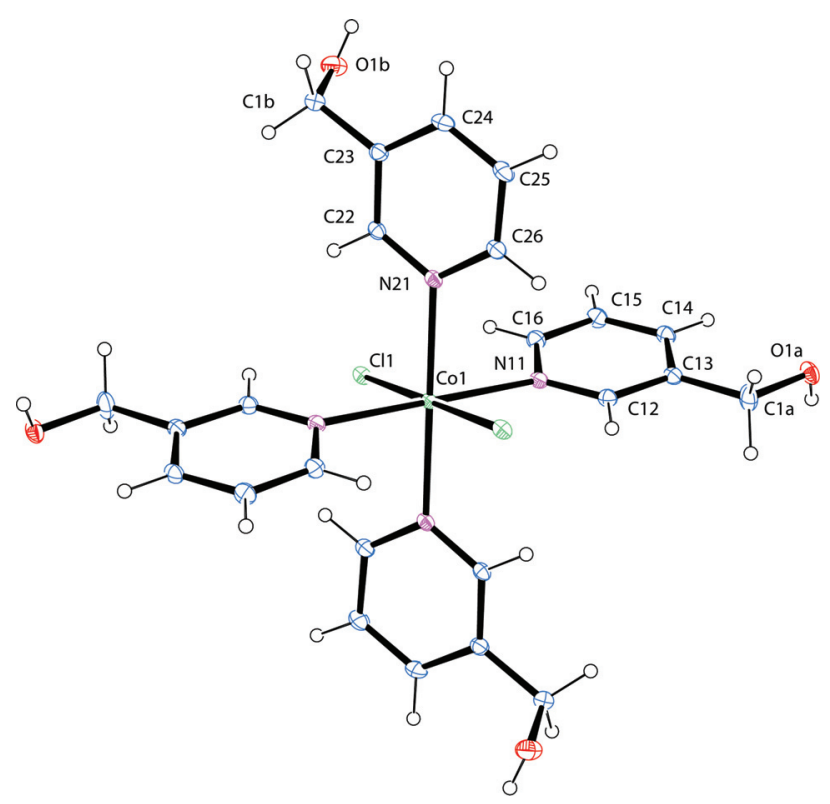

Figure 2. ORTEP view of $\mathrm{CoCl}_{2}(3 \mathrm{PM})_{4}$ molecule in $\mathbf{1}$. Thermal ellipsoids are drawn at the $25 \%$ probability level. Only the atoms of the asymmetric unit are labelled. Due to the similarity of the molecular entities the labelling scheme pertains also to 2 and $\mathbf{3}$.
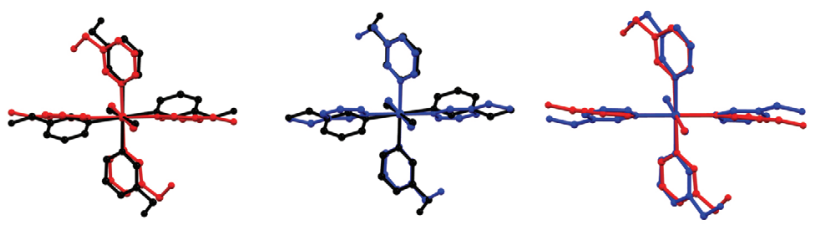

Figure 3. Left: Superposition of $\mathrm{CoCl}_{2}(3 \mathrm{PM})_{4}$ molecules in $\mathbf{1}$ (black) and 2 (red). Center: Superposition of $\mathrm{CoCl}_{2}(3 \mathrm{PM})_{4}$ molecules in 1 (black) and 3 (blue). Right: Superposition of $\mathrm{CoCl}_{2}(3 \mathrm{PM})_{4}$ molecules in $\mathbf{2}$ (red) and $\mathbf{3}$ (blue). Hydrogen atoms were omitted for clarity.

monodentate fashion through endocyclic nitrogen atom. The chlorides are occupying the axial sites. The selected geometric parameters are listed in Table 2. While the Co-N distances are comparable for the two distinct ligands $(2.2050,2.2016 \AA)$ in $\mathbf{3}$, they differ for $0.03 \AA$ and $0.08 \AA$ in $\mathbf{1}$ and $\mathbf{2}$, respectively. The $\mathrm{Co}-\mathrm{Cl}$ distance in $\mathbf{2}$ $(2.5167(5) \AA)$ is a bit longer than the corresponding values of 2.4874(4) and 2.4844(6) $\AA$ for compounds 1 and 3 , respectively. The molecular entities, however, differ in the orientation of 3-pyridinemethanol ligands. The superposition of $\mathbf{1}$ and $\mathbf{2}$ and the superposition of $\mathbf{1}$ and $\mathbf{3}$ are presented in Figure 3.

\section{2. Packing}

The most striking difference in the molecular structures of the two polymorphs (beside the rotation of the pyridine ring) is the orientation of the hydroxymethyl
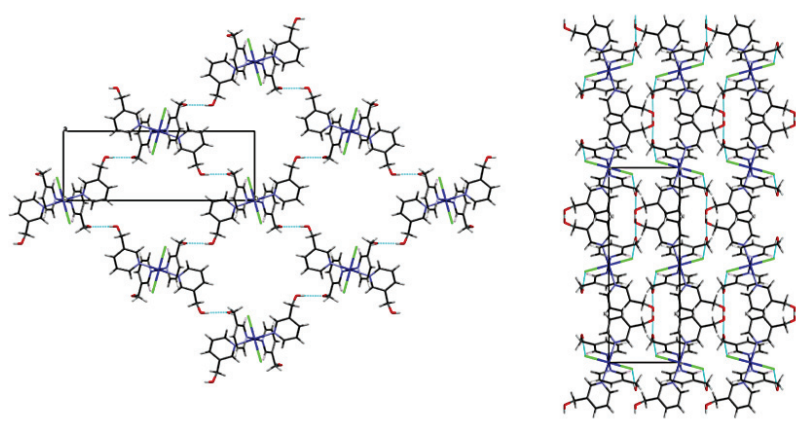

Figure 4. A layer of molecules in polymorph 1 connected by hydrogen bonds between the hydroxyl groups viewed along a axis (left) and formation of a three-dimensional structure through additional $\mathrm{O}-\mathrm{H} \cdots \mathrm{Cl}$ hydrogen bond (right) viewed along $c$ axis.

Table 2. Selected bond lengths $(\AA)$ and angles $\left(^{\circ}\right)$ for $\mathbf{1}, \mathbf{2}$ and $\mathbf{3}$.

\begin{tabular}{llllll}
\hline $\mathbf{1}$ & \multicolumn{3}{c}{$\mathbf{3}$} & & \\
\hline Co1-N21 & $2.1886(13)$ & Co1-N21 & $2.1559(15)$ & Co1-N21 & $2.2050(19)$ \\
Co1-N11 & $2.2345(13)$ & Co1-N11 & $2.2367(16)$ & Co1-N11 & $2.2016(19)$ \\
Co1-Cl1 & $2.4874(4)$ & Co1-Cl1 & $2.5167(5)$ & Co1-Cl1 & $2.4844(6)$ \\
N21-Co1-N11 & $83.78(5)$ & N21-Co1-N11 & $94.95(6)$ & N21-Co1-N11 & $86.13(7)$ \\
N21-Co1-Cl1 & $89.77(4)$ & N21-Co1-Cl1 & $89.56(4)$ & N21-Co1-Cl1 & $88.80(5)$ \\
N11-Co1-Cl1 & $91.31(4)$ & N11-Co1-Cl1 & $91.47(4)$ & N11-Co1-Cl1 & $90.61(5)$ \\
\hline
\end{tabular}


groups attached to the ring of the 3PM ligands. This affects the possible formation of hydrogen bonds and results in different packing arrangement. In the monoclinic polymorph 1, two types of $\mathrm{H}$-bonds are observed. One hydroxyl group (O1B-H1B) acts as a donor to a hydroxyl oxygen atom O1A of the neighbouring molecule. Taking into account the symmetry of the crystal, 2D-layers are formed which are oriented parallel to the face C. Hydroxyl group O1A-H1A connects the layers into 3D network through the additional hydrogen bond to the chloride ion of the adjacent molecule (Figure 4). Details of the hydrogen-bonding geometry are listed in Table 3.

Packing of the polymorph $\mathbf{2}$ is governed by the same type of hydrogen bonds as observed in $\mathbf{1}$. Different orientation of the hydroxymethyl tail and the overall crystal symmetry results in the formation of $2 \mathrm{D}$ layers. The hydroxyl group O1B-H1B serves as a donor to the hydroxyl oxygen $\mathrm{O} 1 \mathrm{~A}$ of the adjacent molecule, related by the inversion center. The result is the formation of the infinite chains running along the $a c$ diagonal. The chains are further connected through $\mathrm{O} 1 \mathrm{~A}-\mathrm{H} 1 \mathrm{~A} \cdots \mathrm{Cl} 1$ into 2D layers almost perpendicular to the $a c$ diagonal.

The two polymorphs have slightly different densities of 1.563 and $1.519 \mathrm{~g} / \mathrm{cm}^{3}$ for polymorph $\mathbf{1}$ and $\mathbf{2}$, res-

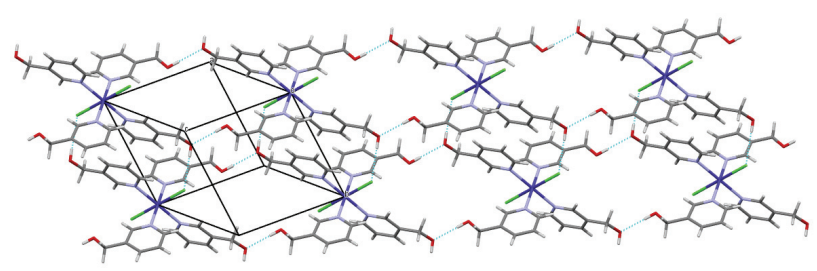

Figure 5. A perpendicular view of a two dimensional layer of hydrogen-bonded $\mathrm{CoCl}_{2}(3 \mathrm{PM})_{4}$ molecules in polymorph 2 .

Table 3. Hydrogen bond distances $(\AA)$ and angles $\left(^{\circ}\right)$ in 1, 2 and $\mathbf{3}$. Due to the fact that the positions of the hydrogen atoms of the water molecule in 3 could not be refined properly, only donor-acceptor distances of potential hydrogen bonds are tabulated.

\begin{tabular}{|c|c|c|c|c|}
\hline$\overline{D-H} \cdots A$ & D-H & $H \cdots A$ & $\mathbf{D} \cdots \mathbf{A}$ & $D-\mathbf{H} \cdots A$ \\
\hline \multicolumn{5}{|l|}{1} \\
\hline$\overline{\mathrm{O} 1 B-\mathrm{H} 1 B \cdots \mathrm{O} 1 A^{\mathrm{i}}}$ & $0.79(3)$ & $2.01(3)$ & $2.7939(19)$ & $174(2)$ \\
\hline $\mathrm{O} 1 A-\mathrm{H} 1 A \cdots \mathrm{C} 11^{\mathrm{ii}}$ & $0.82(2)$ & $2.35(3)$ & $3.1601(13)$ & $172(2)$ \\
\hline \multicolumn{5}{|l|}{2} \\
\hline$\overline{\mathrm{O} 1 \mathrm{~A}-\mathrm{H} 1 \mathrm{~A} \cdots \mathrm{Cl} 1^{\mathrm{iii}}}$ & $0.79(3)$ & $2.42(3)$ & $3.1997(16)$ & 173(3) \\
\hline $\mathrm{O} 1 \mathrm{~B}-\mathrm{H} 1 \mathrm{~B} \cdots \mathrm{O} 1 \mathrm{~A}^{\mathrm{iv}}$ & $0.82(4)$ & $1.96(4)$ & $2.784(3)$ & $176(4)$ \\
\hline \multicolumn{5}{|l|}{3} \\
\hline $\mathrm{O} 1 A-\mathrm{H} 1 A \cdots \mathrm{Cl} 1{ }^{\mathrm{iii}}$ & 0.84 & 2.23 & $3.0706(17)$ & 176 \\
\hline $\mathrm{O} 1 W \cdots \mathrm{O} 1 \mathrm{~B}$ & & & $2.702(3)$ & \\
\hline $\mathrm{O} 1 W \cdots \mathrm{O} 1 \mathrm{~A}^{\mathrm{v}}$ & & & $2.783(3)$ & \\
\hline $\mathrm{O} 1 W \cdots \mathrm{O} 1 \mathrm{~W}^{\mathrm{vi}}$ & & & $2.744(4)$ & \\
\hline
\end{tabular}

Symmetry codes: (i) $x+1,-y+1 / 2, z-1 / 2$; (ii) $-x,-y,-z+1$; (iii) $-x,-y+1,-z$; (iv) $-x-1,-y,-z-1$; (v) $x, y-1, z$; (vi) $-x+1,-y-$ $1,-z+1$ pectively. The energetically most stable arrangement of molecules is expected to have the strongest interactions between the molecules, the most efficient packing and hence the highest density. According to the 'density rule' one can conclude that the polymorph $\mathbf{1}$ is more stable than 2 which is in agreement with the observation of very low content of polymorph $\mathbf{2}$ in the bulk crystalline product obtained from the reaction mixture. ${ }^{8,19-22}$

The crystal form 3 contains one water molecule per asymmetric unit (two per molecule) which is included in the hydrogen-bonding network. No interactions were observed between the two hydroxyl groups, however one $(\mathrm{O} 1 \mathrm{~A}-\mathrm{H} 1 \mathrm{~A})$ interacts with a chloride from the adjacent molecule. The position of hydrogen atoms of a water molecule could not be determined, therefore no $\mathrm{H}$-bond geometry is available. However, water molecule is included in hydrogen bonding network, which can be draw from the distances of water oxygen atom to the neighbouring atoms. The shortest distances are listed in Table 3. The O1A-H1A … Cl1 hydrogen bond connects the molecules into linear chains running along the $b$ axis. Further bonding includes water molecule, consequently three-dimensional $\mathrm{H}$-bonded network is formed. (Figure 6).

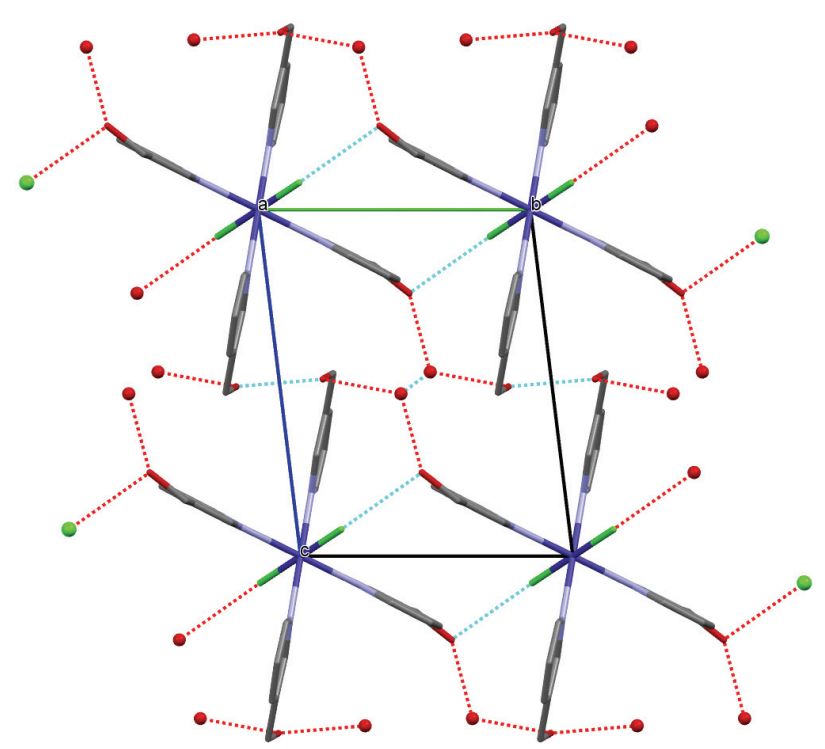

Figure 6. Three dimensional H-bonded network in 3, viewed along $a$ axis. D $\cdots$ A contacts are drawn as red dotted lines. Hydrogen atoms are omitted.

The packing arrangements of all three forms are additionally stabilised by parallel displaced $\pi \cdots \pi$ stacking interaction between the symmetry related pyridine rings. In 1 this interaction connects the molecules into chains propagating along the $c$ axis In $\mathbf{2}$, a similar $\pi \cdots \pi$ stacking interaction between the symmetry related pyridine rings connects molecules belonging to the neighbouring layers 
formed by hydrogen bonding in chains propagating along the $b$ axis. In $\mathbf{3}$, the parallel displaced $\pi \cdots \pi$ stacking interaction again connects the molecules in chains propagating along the $b$ axis. The interactions are analogous to those in the triclinic polymorph 2 . Additionally, T-shaped $\mathrm{C}-\mathrm{H} \cdots \pi$ hydrogen bonds between the aromatic $\mathrm{C}-\mathrm{H}$ moiety of the $\mathrm{N} 11 \cdots \mathrm{C} 16$ pyridine ring and the $\mathrm{N} 21 \cdots \mathrm{C} 26$ pyridine ring belonging to a neighbouring molecule help to stabilise all three crystal forms. The donor-acceptor distances are: $3.558(17) \AA$ in the monoclinic polymorph $\mathbf{1}$, 3.605(3) $\AA$ in the triclinic polymorph 2 and 3.587(3) $\AA$ in the dihydrate $\mathbf{3}$.

\section{Conclusions}

Our research, originally aimed to the preparation of new polynuclear coordination compounds with simple pyridine alcohol ligands, failed. Instead two new polymorphs and a dihydrate of cobalt chloride with 3-pyridinemethanol were discovered. The structures of the two concomitantly crystallised forms are herein compared revealing their significantly different molecular geometries and packing arrangements.

\section{Supplementary Material}

CCDC 1020901, CCDC 1020902 and CCDC 1020903 contain the supplementary crystallographic data for this paper. The data can be obtained free of charge from The Cambridge Crystallographic data centre via www.ccdc.cam.ac.uk/data/request/cif.

\section{Acknowledgement}

The financial support of the Slovenian Research Agency (ARRS) through P1-0175 grant and junior research grant for M. T. is gratefully acknowledged. The EN-FIST Centre of Excellence is acknowledged for the use of the SuperNova diffractometer.

\section{References}

1. CrystEngComm 2013, 15, Themed issue: Structural Design of Coordination Polymers.

\section{Povzetek}

Pripravili smo nov monomeren kobaltov klorid z enostavnim piridinskim alkoholom 3-piridinmetanolom (3PM) kot enoveznim ligandom. Spojina $\mathrm{CoCl}_{2}(3 \mathrm{PM})_{4}$ hkrati kristalizira v treh različnih oblikah: v dveh polimorfnih oblikah, trinklinski $(P \overline{1})$ in monoklinski $\left(P 2_{1} / c\right)$, ter kot dihidrat v triklinski prostorski skupini $P \overline{1}$. Strukture se razlikujejo po prostorski orientaciji 3PM ligandov $\mathrm{v}$ molekulah $\mathrm{CoCl}_{2}(3 \mathrm{PM})_{4}$ in posledično tudi po razporeditvi monomernih enot $\mathrm{v}$ kristalni strukturi. Vse tri strukture so bile določene pri $150 \mathrm{~K}$.
2. C. B. Aakeröy, N. R. Champness, C. Janiak, CrystEngComm 2010, 12, 22-43. http://dx.doi.org/10.1039/B919819A

3. S. Noro, S. Kitagawa, M. Kondo, K. Seki, Angew. Chem. Int. Ed. 2000, 39, 2081-2084. http://dx.doi.org/10.1002/15213773(20000616)39:12<2081::AID-ANIE2081>3.0.CO;2-A

4. S. L. James, Chem. Soc. Rev. 2003, 32, 276-288. http://dx.doi.org/10.1039/b200393g

5. S. Ehrlich, J. Moellmann, S. Grimme, Acc. Chem. Res. 2012, 46, 916-926. http://dx.doi.org/10.1021/ar3000844

6. C. Janiak, J. Dalton Trans. 2000, 3885-3896.

7. M. Nishio, Y. Umezawa, K. Honda, S. Tsuboyama, H. Suezawa, CrystEngComm 2009, 11, 1757-1788. http://dx.doi.org/10.1039/b902318f

8. J. Bernstein, R. J. Davey, J. O. Henck, Angew. Chem. Int. Ed. 1999, 38, 3440-3461. http://dx.doi.org/10.1002/(SICI)15213773(19991203)38:23<3440::AID-ANIE3440>3.0.CO;2-\#

9. M. Trdin, V. Bergant, I. Leban, N. Lah, Acta Chim. Slov. 2012, 59, 478-483.

10. M. Trdin, N. Lah, Acta Cryst. 2012, C68, m359-m362.

11. Oxford Diffraction (2009). CrysAlis PRO. Oxford Diffraction Ltd, Yarnton, England.

12. A. Altomare, M. C. Burla, M. Camalli, G. L. Cascarano, C. Giacovazzo, A. Guagliardi, A. G. G. Moliterni, G. Polidori, R. Spagna, J. Appl. Cryst. 1999, 32, 115-119. http://dx.doi.org/10.1107/S0021889898007717

13. G. M. Sheldrick, Acta Cryst. 2008, A64, 112-122. http://dx.doi.org/10.1107/S0108767307043930

14. L. J. Farrugia, J. Appl. Cryst. 1997, 30, 565. http://dx.doi.org/10.1107/S0021889897003117

15. C. F. Macrae, I. J. Bruno, J. A. Chisholm, P. R. Edgington, P. McCabe, E. Pidcock, L. Rodriguez-Monge, R. Taylor, J. van de Streek, P. A. Wood, J. Appl. Cryst. 2008, 41, 466-470. http://dx.doi.org/10.1107/S0021889807067908

16. Crystal Maker Software Ltd, Oxford, England (www.crystalmaker.com)

17. F. H. Allen, Acta Cryst. 2002, B58, 380-388. http://dx.doi.org/10.1107/S0108768102003890

18. J. Moncol, M. Mudra, P. Lonnecke, M. Koman, M. Melnik, J. Chem. Cryst. 2004, 34, 423-431. http://dx.doi.org/10.1023/B:JOCC.0000035382.59831.ee

19. J. Bernstein, R. J. Davey, J. O. Henck, Angew. Chem. Int. Ed. 1999, 38, 3440-3461. http://dx.doi.org/10.1002/(SICI)15213773(19991203)38:23<3440::AID-ANIE3440>3.0.CO;2-\#

20. J. Bernstein, Polymorphism in Molecular Crystals 2002, Oxford University Press.

21. D. Braga, F. Grepioni, L. Maini, M. Polito, Structure and Bonding 2009, 132, 25-50. http://dx.doi.org/10.1007/430_2008_7

22. G. Desiraju, Cryst. Growth Des. 2008, 8, 3-5. http://dx.doi.org/10.1021/cg701000q 